\title{
Hypertension, mitral valve disease, atrial fibrillation and low education level predict delirium and worst outcome after cardiac surgery in older adults
}

Fátima R. Oliveira ${ }^{1,3}$, Victor H. Oliveira³, Ítalo M. Oliveira³, José W. Lima², Daniela Calderaro', Danielle M. Gualandro ${ }^{1}$ and Bruno Caramelli ${ }^{1 *}$ (D)

\begin{abstract}
Background: Delirium is a common complication after cardiac surgery in older adult patients. However, risk factors and the influence of delirium on patient outcomes are not well established. We aimed to determine the incidence, predisposing and triggering factors of delirium following cardiac surgery.

Methods: One hundred seventy-three consecutive patients aged $\geq 60$ years were studied. Patients' characteristics and two cognitive function assessment tests were recorded preoperatively. Perioperative variables were blood transfusion, orotracheal intubation time (OIT), renal dysfunction, and hypoxemia. Delirium was assessed using the Confusion Assessment Method for the Intensive Care Unit. The composite outcome consisted of death, infection, and perioperative myocardial infarction until hospital discharge or 30 days after surgery, and for up to 18 months.

Results: One hundred six patients (61.27\%) were men and the age was $69.5 \pm 5.8$ years. EuroSCORE II index was 4. $06 \pm 3.86$. Hypertension was present in $75.14 \%$, diabetes in $39.88 \%$, and $30.06 \%$ were illiterate. Delirium occurred in 59 patients (34.1\%). Education level (OR 0.81, 0.71-0.92), hypertension (OR 2.73, 1.16-6.40), and mitral valve disease (OR 2.93, 1.32-6.50) were independent predisposing factors for delirium, and atrial fibrillation after surgery (OR 2.49, 1.20-5.20) represented the potential triggering factor. Delirium (OR 2.35, 1.20-4.58) and OIT $\geq 900$ min (OR 2.50; 1. 30-4.80) were independently associated with the composite outcome.
\end{abstract}

Conclusions: In older adult patients submitted to cardiac surgery, delirium is a frequent complication that is associated with worst outcome. Independent risk factors for delirium included education level, hypertension, mitral valve disease, and atrial fibrillation after cardiac surgery.

Keywords: Delirium, Cardiac surgery, Incidence, Elderly, Illiterate

\section{Background}

Delirium is a transient and fluctuating course condition of acute onset that is characterized by reduced level of consciousness, global cognitive dysfunction, and disorder in the sleep-wake cycle. In patients undergoing cardiac surgery, delirium is a complication that affects $2-57 \%$ of the patients, reaching as high as $73 \%$ in older subjects [1].

\footnotetext{
* Correspondence: bcaramel@usp.br

'Heart Institute (InCor), University of Sao Paulo, Brazil. Av. Dr. Enéas Carvalho de Aguiar 44, Sao Paulo, CEP, São Paulo 05403-000, Brazil

Full list of author information is available at the end of the article
}

Delirium has a multifactorial etiology. Several risk factors for delirium after cardiac surgery have been described in the literature as age, depression, anemia, atrial fibrillation before intervention as predisposing factors; and orotracheal intubation time (OIT), extracorporeal circulation time, hypoxemia as precipitating factors [2-5]. It seems that the complex interaction between these factors is responsible for the development of delirium. Low educational level has also been studied as a risk factor for delirium after surgery but never in a group of very low educational level that includes a significant rate of illiteracy. 
Postoperative delirium is strongly associated with higher morbidity and mortality [6]. The identification of patients at high risk for delirium is important to deliver proper care and avoid the consequences of this complication. The objective of this research was to determine the incidence, predisposing factors, and triggering factors of delirium following cardiac surgery and its consequences within 30 days of surgery and during a 12-18-month follow-up in older adult patients with a significant rate of illiteracy.

\section{Methods}

\section{Population}

This was an observational prospective cohort study at Messejana Hospital, a tertiary Hospital in Fortaleza, Brazil. Between September 2011 and December 2013 a group of 609 patients underwent cardiac surgery. Of these, 342 patients were aged $\geq 60$ years, an inclusion criterion. The exclusion criteria included blindness, deafmuteness, previous diagnosis of dementia confirmed by specialist, permanently bedridden due to sequel from a cerebrovascular accident, creatinine clearance $<30 \mathrm{~mL} /$ min or on dialysis, emergency cardiac surgery, surgery combined with vascular procedures such as carotid endarterectomy or aortic aneurysm repair, post-infarction inter-ventricular communication correction, isolated congenital heart disease, or the presence of delirium at the preoperative interview. Local ethical committee (CAPPesq) has approved the protocol under the number 825/ 11. Informed consent was obtained from all patients according to international guidelines.

\section{Clinical, surgical variables and outcomes}

Demographic and clinical characteristics as well as the presence of comorbidities were obtained at preoperative evaluation. Preoperative tests included electrocardiogram, echocardiogram, carotid ultrasonography, coronariography, and cardiac troponin I. At this time, the cognitive function of patients was assessed using the mini mental state examination (MMSE) adjusted for education level according to Bertolucci's classification [7], and the verbal fluency test, including words from the animal category (VFT), also adjusted for education level [8].

For evaluation of preoperative delirium, the confusion assessment method (CAM) was applied by two researchers, and diagnosis was determined by the presence of criteria 1 and 2 plus either criteria 3 or 4 [9]. Data related to the intervention were also recorded: duration of surgery and anesthesia, cardiopulmonary bypass or aortic clamping time (when used), and transfusion of blood components.

Postoperative variables included hematocrit and hemoglobin values obtained immediately after patient's arrival in the intensive care unit (ICU), OIT, and date of hospital discharge and/or death. To detect postoperative delirium, patients were observed daily from the first postoperative day in the ICU until hospital discharge. Owing to its ability to be used in mechanically ventilated patients, the CAM-ICU tool [10] was performed during ICU stay. The diagnosis was confirmed according to the criteria of the Diagnostic and Statistical Manual of Mental Disorders (DSM-IV) [11]. The diagnosis of hypoxemia required a ratio of $\mathrm{PaO} 2 / \mathrm{FIO} 2<200$ analyzed at least once daily in the immediate postoperative and in the third day thereafter in patients on mechanical ventilation or breathing spontaneously, and renal dysfunction was determined using RIFLE the criteria [12].

The consequences of delirium were evaluated up to 30 days after surgery using the composite endpoint, consisting of death from all causes, infections, and perioperative acute myocardial infarction (AMI). Infection was defined based on criteria established by National guidelines for health care-related infections [13]. Only serious nosocomial infections requiring treatment with intravenous antibiotics during the same hospital stay were captured.

For the diagnosis of perioperative AMI, electrocardiographic criteria and troponin I (>10 times the 99th percentile of the upper reference limit) were used as markers of myocardial injury, measured in the first, third, and fifth postoperative day.

Patients were followed up for 12 to 18 months at the outpatient clinic and were reassessed for diagnosis of dementia using MMSE and VFT.

\section{Statistical analysis of data}

Descriptive statistics such as means, standard deviations, frequencies and percentages were computed. Continuous variable distributions were compared using t-test for independent or paired samples, or Mann-Whitney U tests, as appropriate. Proportions were compared using Pearson's Chi Squared or Fisher's Exact tests. The relationship between variables and delirium or composite outcome was assessed through simple logistic regression.

Initially, reported variables associated to delirium described in the literature [4], and variables associated to delirium with $p$-value $\leq 0.1$ in the present study, were eligible for the multivariate analysis. Altogether, there were seventeen potential predictor variables. Taking in account the number of events of delirium in the study sample (59 events), and the number of variables in a multivariate model, which would include seventeen predictor variables [14], we decided to use a stepwise forward selection, with backward elimination modeling strategy [15]. Model building was processed with forward variable selection and backward variable deletion. 
Initially, we developed a reference model with the intercept followed by simple regression models, one for each independent variable. Each independent variable model was compared with the reference model through the Likelihood Ratio Test (LRT). The independent variable with the smallest $P$-value, smaller than 0.2 (entry criteria), was the first variable selected. This simple logistic model was used for the next step of variable selection. This process was repeated until the independent variable with the smallest $p$-value was equal or greater than 0.2. When a new variable was included in a model, logistic models excluding one independent variable, one at a time, were compared with the full model. The independent variable with the highest LRT $\mathrm{p}$-value greater than 0.4 was excluded (deletion criteria). The same procedures described before were adopted to build a model of the composite outcome. MMSE and the VFT were evaluated as continuous variables and the values were compared before surgery and after 1 year of their completion.

Kaplan-Meier curves were compared by means of LogRank Test for equality of survivor functions. All statistics tests were two-tailed and a $P$-value smaller than 0.05 was accepted as statistically significant.

\section{Results}

\section{General characteristics of the patients in the study}

After exclusion criteria, 179 were included in the study. Final sample was reduced to 173 patients as the presence of delirium could not be evaluated in six. Flow chart showing the process of including patients in the study is depicted in Fig. 1. General characteristics of the study population is shown in Table 1 . A total of 148 $(85.5 \%)$ patients were using beta-blockers, 152 (87.6\%) were taking statins, 120 (69.3\%) were using aspirin the day before surgery, and only eleven (6.4\%) were using antidepressants. The level of education was low considering the average of $3.05 \pm 3.08$ years and illiteracy rate of $30.1 \%$. In $109(63.0 \%)$ patients, a coronary angiography revealed three-vessel or left main coronary artery lesions and thirty-two (18.5\%) had no significant coronary disease. Forty-three (24.9\%) patients had mitral valve disease, and thirty (17.3\%) had aortic valve disease detected by Doppler echocardiography. The ultrasound of carotid and vertebral arteries revealed obstructive lesions $\geq 70 \%$ in 10 patients $(5.8 \%)$, and $79(46.2 \%)$ showed no obstruction. Of the 173 patients, 114 (65.9\%) underwent isolated coronary artery bypass graft (CABG), eighteen (10.4\%) had aortic prosthesis implantation, twenty-one (12.1\%) received mitral prosthesis, and four (2.3\%) had both mitral and aortic prosthesis implants. Finally, in sixteen (9.2\%) patients, CABG was associated with repair and/or implant of a prosthetic valve.
The incidence of delirium was 34.1\%; in 41 (69.5\%) it was detected in the first two postoperative days, in nine $(15.2 \%)$ on the third day, in six $(10.2 \%)$ on the fourth day, and in three $(5.1 \%)$ on the fifth day. Hyperactive delirium was found in seventeen (28.8\%) patients, hypoactive delirium in 24 (40.7\%), and mixed delirium in eighteen (30.5\%). The overall mortality rate was 12.1\%. In-hospital death occurred in ten (5.8\%) patients, and eleven (6.3\%) died after hospital discharge. Of these, $9(42,8 \%)$ had postoperative delirium and 12 $(57,2 \%)$ did not.

Perioperative variables and their relationship with delirium Age, low educational level, mitral valve disease, preoperative MMSE and VFT, aortic clamping time, postoperative renal dysfunction, atrial fibrillation detected after cardiac surgery and troponin I measured in the first day post-surgery were the risk factors identified in univariate analysis Table 2.

MMSE adjusted according to the patient's education level revealed that only thirteen (7.5\%) patients had preoperative cognitive deficit; in five (38.5\%) of these, the diagnosis of delirium was made after surgery. We observed no association between delirium and the preexistence of cognitive deficit. Among those who did not have previous cognitive deficit, delirium was present after intervention in 54 (33.7\%). However, there was a significant association of low education level with delirium Table 2.

Similarly, VFT results adjusted by education level detected $70(40.5 \%)$ patients with cognitive deficit. Of these, twenty-eight (40\%) had delirium. In those patients without cognitive deficit by the VFT, delirium occurred in thirty-one (30.1\%). However, we observed no association of education-adjusted VFT and the occurrence of delirium.

The preoperative variables listed in Table 2 were used to identify the predisposing factors for delirium, while perioperative variables covered the model identifying triggering factors in the multivariate analysis. Data are shown in Table 3.

\section{Delirium as a risk factor for the composite outcome and clinical follow-up}

Univariate analysis showed that delirium, OIT time $\geq$ $900 \mathrm{~min}$ and time in the intensive care unit were associated to the composite outcome (death, postoperative infection and perioperative myocardial infarction). Results are depicted on Table 4. Multiple logistic regression model was created with the variables listed in Table 4 to identify significant factors for the occurrence of the composite outcome. Data are shown in Table 5.

Of the 173 patients, 144 completed the follow-up. Comparison of data from patients before and 12- 


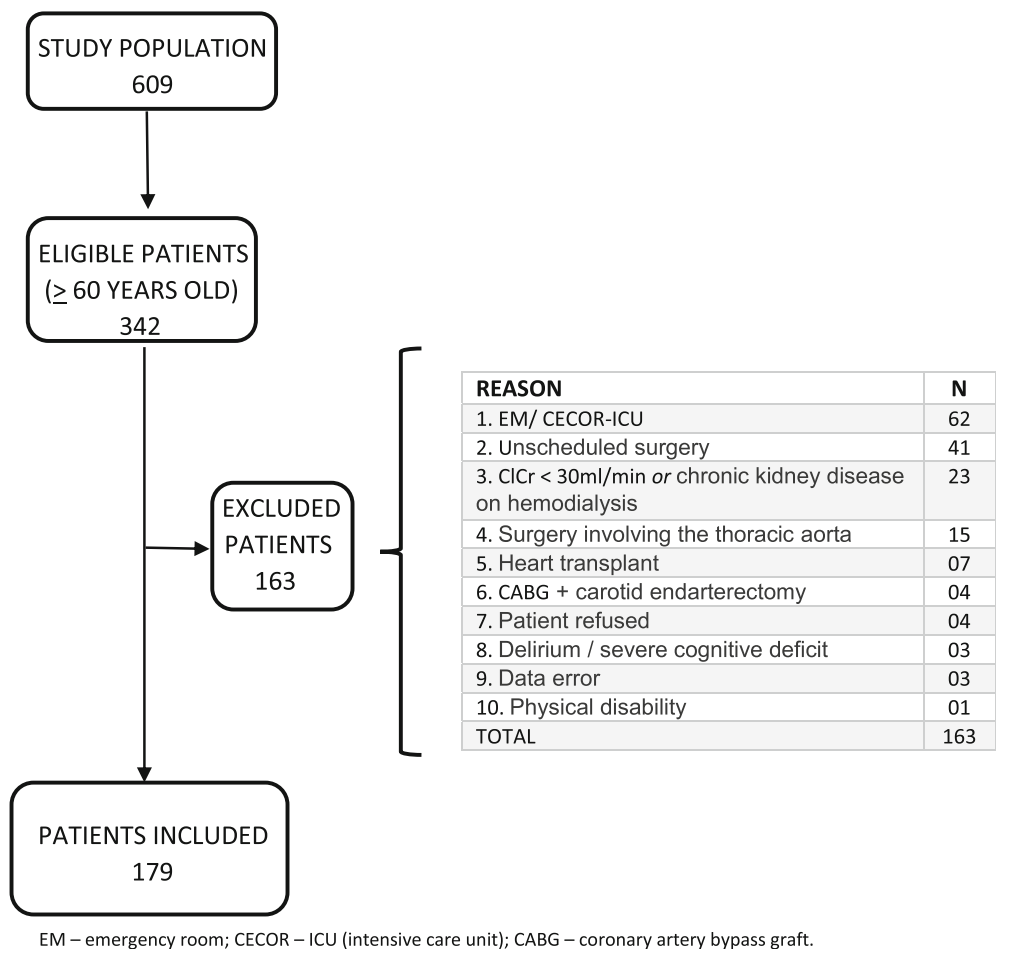

Fig. 1 Study population flowchart

18 months after surgery, showed no differences between those with and without delirium: MMSE $(24.0 \pm 4.1$ and $21.8 \pm 4.8$, before, $24.5 \pm 3.6$ and $22.4 \pm 4.4$, after 12 18 months, respectively, $P=0.38)$ and VFT $(10.9 \pm 3.9$ and $9.1 \pm 3.2$, before, $12.4 \pm 3.7$ and $10.9 \pm 4.1$, after $12-$ 18 months, respectively, $P=0.51$ ). Thirty patients were readmitted after performing heart surgery, leading to a re-hospitalization rate of $20 \%$. Of these, nine (30\%) had postoperative delirium after cardiac surgery. There was no association between delirium and readmission $(P=0.73)$. Importantly, there was significant association between delirium and in-hospital mortality $(P=0.03)$. Time do death Kaplan-Meier curve is depicted in Fig. 2. Conversely, no association was observed between delirium and post discharge mortality $(P=0.50)$.

\section{Discussion}

The incidence of delirium in the present study is consistent with previous reports using similar variables such as age, type of surgery, and the CAM-ICU scale for assessing delirium [5]. A precipitant risk factor for the development of delirium described in the literature is the intensive care environment. In this study, all patients were admitted to an intensive care unit after cardiac surgery, but only 59 patients (34.1\%) had delirium. In a recent study, researchers evaluated the relationship between the harmful environment of the ICU and the onset of delirium in postoperative cardiac surgery and found no significant association [16]. It is likely that the complex interaction between several risk factors favors the development of delirium and not the influence of a single one.

In the present study, low education level was an independent predictor of the occurrence of delirium. Considering that education level is frequently considered a proxy of cognitive reserve, we expected that the association between cognitive decline (comparing pre- and 12-18 months post-op test scores) and the occurrence of delirium would be significant. The association between education level and delirium has been previously investigated $[17,18]$ but data involving illiterate individuals submitted to cardiac surgery is lacking. Our findings can be explained by the fact that individuals who experience stimuli throughout life, such as literacy development in childhood and physical exercise, may delay the onset of dementia and its consequences [18]. Recently published work has revealed that postoperative delirium is associated with greater cognitive decline and a higher incidence of dementia up to 15 months after surgery [19]. Another study involving only with patients undergoing cardiac surgery revealed that postoperative delirium was associated with cognitive decline one month after surgery but this phenomenon disappeared when patients were re-evaluated after one year, suggesting possible recovery of cognitive function over time [20]. Literature data are still conflicting about the time of 
Table 1 Baseline clinical characteristics of the patients in the study $(n=173)$

\begin{tabular}{|c|c|}
\hline Variables & Values \\
\hline $\mathrm{Age}^{\mathrm{a}}$ & $69.50 \pm 5.80$ \\
\hline Male & $106(61.3 \%)$ \\
\hline Body mass índex ${ }^{a}$ & $26.20 \pm 4.10$ \\
\hline Level of education (years) & $3.05 \pm 3.08$ \\
\hline Illiterate & $52(30.1 \%)$ \\
\hline Systemic arterial hypertension & $130(75.1 \%)$ \\
\hline Diabetes mellitus & $69(39.9 \%)$ \\
\hline Dyslipidemia & $123(71.1 \%)$ \\
\hline Previous stroke & $27(15.6 \%)$ \\
\hline \multicolumn{2}{|l|}{ Smoking } \\
\hline Non smoker & $123(71.1 \%)$ \\
\hline Current smoker & $30(17.3 \%)$ \\
\hline Ex-smoker & $20(11.6 \%)$ \\
\hline Alcohol consumption & $34(19.6 \%)$ \\
\hline EurOSCORE $\|^{a}$ & $4.06 \pm 3.86$ \\
\hline Ejection fraction (ECO) ${ }^{a}$ & $0.53 \pm 0.12$ \\
\hline Cardiac rhythm (sinus rhythm) & $153(88.4 \%)$ \\
\hline Pre MMSE ${ }^{\mathrm{a}}$ & $23.27 \pm 4.51$ \\
\hline Pre $\mathrm{VFT}^{\mathrm{a}}$ & $10.31 \pm 3.75$ \\
\hline Pre $\mathrm{ClCr}^{\mathrm{a}}$ & $60.73 \pm 19.74$ \\
\hline
\end{tabular}

ECO Doppler echocardiography, MMSE Mini-mental state examination, VFT Verbal fluency test, $\mathrm{ClCr}$ Creatinine clearance

${ }^{\text {a } C o n t i n u o u s ~ v a r i a b l e s ~ a r e ~ d e s c r i b e d ~ a s ~ m e a n s ~ a n d ~ s t a n d a r d ~ d e v i a t i o n . ~ O t h e r ~}$ variables are described as absolute and percentage values

development of the cognitive deficit after postoperative delirium depending on the population studied, the length of follow-up, and the tools used for evaluation. [21-24]. We hypothesize that the relative short followup time of 12-18 months was not enough to detect a difference. In other words, in this 12-18 months followup study, having baseline low education level likely associated to low cognitive reserve and not cognitive decline could represent a factor of vulnerability of the brain and a risk factor for neurological disorders such as delirium or dementia.

The second independent risk factor for delirium identified in this study was hypertension. Previous research has shown that patients with hypertension are at a higher risk of developing delirium, after cardiac surgery $[25,26]$ or in the ICU [27-29]. The third independent risk factor for delirium in the present study was the presence of mitral valve disease. To date, there are no data in the literature showing this association. In our sample, there were 43 patients with mitral valve disease and 17 of them had also atrial fibrillation. We speculate that the simultaneous conditions like mitral valve disease, atrial fibrillation in patients with a large left atrium
Table 2 Pre, trans, and post-operative variables and their relationship with delirium

\begin{tabular}{llll}
\hline Variable & Delirium & & $p$ \\
\cline { 2 - 3 } & No $(n=114)$ & Yes $(n=59)$ & \\
\cline { 1 - 2 } Preoperative variables & & & \\
Male & $75(65.79 \%)$ & $31(52.54 \%)$ & 0.09 \\
Age & $68.80 \pm 5.63$ & $70.80 \pm 6.05$ & 0.03 \\
Education level (years) & $3.59 \pm 3.19$ & $2.00 \pm 2.55$ & $<0.01$ \\
Hypertension & $81(71.05 \%)$ & $49(83.05 \%)$ & 0.08 \\
Statin use & $104(91,2 \%)$ & $48(81.35 \%)$ & 0.06 \\
EuroSCORE II & $3.65 \pm 3.91$ & $4.83 \pm 3.65$ & 0.06 \\
Valve disease & & & \\
$\quad$ Mitral valve disease & $22(19.29 \%)$ & $21(35.59 \%)$ & $<0.01$ \\
$\quad$ Aortic valve disease & $18(15.78 \%)$ & $12(20.33 \%)$ & 0.14 \\
Pre MMSE & $24.04 \pm 4.15$ & $21.79 \pm 4.85$ & $<0.01$ \\
Pre VFT & $10.92 \pm 3.88$ & $9.11 \pm 3.21$ & $<0.01$ \\
CICr (mL/min) & $62.60 \pm 19.80$ & $57.00 \pm 19.10$ & 0.07 \\
Trans/post-operative variables & & & \\
Anesthesia time (min) & $274.10 \pm 60.62$ & $290.10 \pm 57.11$ & 0.09 \\
CPB time (min) & $64.99 \pm 52.83$ & $81.55 \pm 59.90$ & 0.06 \\
Aortic clamping time (min) & $42.83 \pm 38.90$ & $58.88 \pm 46.98$ & 0.02 \\
Hypoxemia & $36(31.58 \%)$ & $27(45.76 \%)$ & 0.06 \\
Renal dysfunction & $19(16.66 \%)$ & $18(30.51 \%)$ & 0.03 \\
AF post-surgery & $26(22.8 \%)$ & $28(47.45 \%)$ & $<0.01$ \\
Troponin I [1] & $6.62 \pm 8.84$ & $12.84 \pm 17.47$ & $<0.01$ \\
\hline
\end{tabular}

MMSE Mini-mental state examination, VFT Verbal fluency test, $\mathrm{CICr}$ Creatinine clearance, $C P B$ time Cardiopulmonary bypass time, AF Atrial fibrillation; Troponin I [1]: troponin dosed in the first day after surgery

leading to microembolization phenomena could be responsible for the greater occurrence of delirium. These microemboli could lead to cerebral ischemia, and hypoperfusion of some regions of the brain that could represent the mechanism for the onset of delirium. Published studies have indeed revealed the presence of micro-emboli during cardiac surgery detected by imaging

Table 3 Multivariate model of risk factors for delirium after cardiac surgery

\begin{tabular}{lllll}
\hline Variable & OR & Standard error & $95 \% \mathrm{Cl}$ & $p$ value \\
\hline $\begin{array}{l}\text { Predisposing factors } \\
\text { Education level (years) }\end{array}$ & 0.81 & 0.05 & $0.71-0.92$ & $<0.01$ \\
$\begin{array}{l}\text { Systemic arterial } \\
\text { hypertension }\end{array}$ & 2.73 & 1.18 & $1.16-6.40$ & 0.02 \\
Valve disease & & & & \\
$\quad \begin{array}{llll}\text { Mitral valve disease } \\
\text { Aortic valve disease }\end{array}$ & 2.93 & 1.19 & $1.32-6.50<0.01$ \\
Triggering factors & 1.55 & 0.71 & $0.63-3.84$ & 0.33 \\
AF post-surgery & & & & \\
\hline
\end{tabular}

OR Odds ratio, 95\% Cl 95\% confidence interval, AF Atrial fibrillation 
Table 4 Pre, trans, and postoperative variables and their relationship to the composite outcome

\begin{tabular}{llll}
\hline Variable & OR & $95 \% \mathrm{Cl}$ & $p$ value \\
\hline Male & 0.59 & $0.32-1.11$ & 0.10 \\
Age & 1.04 & $0.99-1.10$ & 0.07 \\
Diabetes mellitus & 1.54 & $0.82-2.87$ & 0.17 \\
Carotid ultrasonography & 1.63 & $0.85-3.11$ & 0.13 \\
Length of stay in ICU & 1.22 & $1.10-1.36$ & $<0.01$ \\
Renal dysfunction postoperative & 1.93 & $0.92-4.03$ & 0.07 \\
Delirium & 2.67 & $1.39-5.11$ & $<0.01$ \\
OTIT $\geq 900$ min & 2.79 & $1.50-5.20$ & $<0.01$ \\
Postoperative AF & 1.76 & $0.91-3.39$ & 0.08 \\
\hline
\end{tabular}

OR Crude odds ratio, 95\% Cl 95\% confidence interval, ICU Intensive care unit, OTIT Orotracheal intubation time, AF Atrial fibrillation

exams such as transcranial Doppler but the results remain contradictory [30, 31].

Atrial fibrillation after surgery was also identified as an independent precipitant risk factor for delirium after cardiac surgery in our sample. Recent studies have similar results [32-34]. The occurrence of atrial fibrillation postoperatively and its association with delirium favors the hypothesis of cerebral embolism and/or hypotension leading to a reduction of cerebral perfusion that can explain the pathophysiology of delirium [35, 36]. However, persistent atrial fibrillation preoperatively, in this study, was not a predictor of delirium after intervention.

On the other hand, we found that delirium was an independent risk factor for the composite outcome consisting of death, infection, and perioperative myocardial infarction. Several studies have previously identified delirium as a risk factor for increased morbidity and mortality during hospitalization, after one-year and over the long term [6,37-40]. The cause and effect relationship between delirium and infection is not yet fully clear. Mechanisms have been proposed to explain brain dysfunction during sepsis, including disturbances in the production and release of neurotransmitters, changes in cerebral blood flow, and endothelial dysfunction [41]. We also found that OIT was an independent risk factor for the composite outcome. Indeed, ventilator-associated pneumonia (VAP) is the most common nosocomial infection in ICUs. Similarly, the mortality rate for patients with VAP can range from 24 to $50 \%$ [42].

Table 5 Multivariate model of predictor factors to the composite outcome (death, postoperative infection and perioperative myocardial infarction)

\begin{tabular}{lllll}
\hline Variable & OR & Standard error & $95 \%$ Cl & $p$ value \\
\hline Delirium & 2.35 & 0.80 & $1.20-4.58$ & 0.01 \\
OTIT $\geq 900$ min & 2.50 & 0.83 & $1.30-4.80$ & $<0.01$ \\
\hline
\end{tabular}

OR Odds ratio, $95 \%$ CI 95\% confidence interval, OTIT Orotracheal intubation time as a category variable

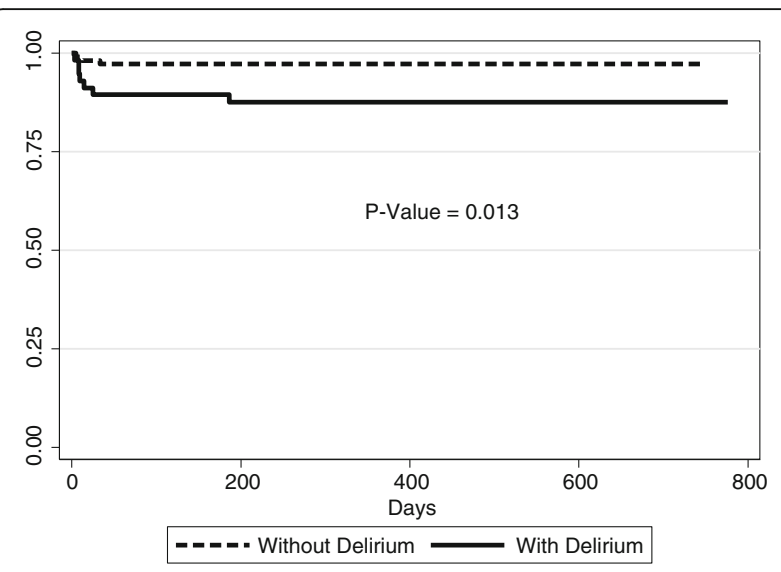

Fig. 2 Time to death Kaplan-Meier Curves for patients with and without delirium

\section{Study limitations}

This research was carried out in a single center and therefore its results cannot be extrapolated to other centers or other populations. A tool for evaluating depression, common in the elderly patient, was not used, which may have some influence in the differential diagnosis between postoperative depression and hypoactive delirium difficult. Since delirium has fluctuating character throughout the day, it may have been underdiagnosed. In addition, the diagnosis of delirium was performed by experienced physicians in critical care medicine but not confirmed by neurologist or psychiatrist. The use of MMSE and VFT as sole evaluation tests of cognitive function may have underdiagnosed patients with Mild Cognitive Impairment (MCI). Finally, is a result of a study that includes the one-year follow-up of patients. We had to wait the one-year follow-up for all patients included in the study. This fact and the complexity of data involving several different aspects of clinical and surgical variables were the main reasons for the relative delay in publishing them.

\section{Conclusions}

In summary, the incidence of delirium in older postcardiac surgery adults was high in the studied population. The variables independently associated with delirium in this study were low education level, hypertension, and the presence of mitral valve disease as predisposing factors, and atrial fibrillation after cardiac surgery as a potential triggering factor. Delirium and prolonged oral intubation time (OIT $\geq 900 \mathrm{~min}$ ) were independently associated with the composite outcome, consisting of all-cause mortality, perioperative myocardial infarction, and infection up to 30 days after surgery. 


\section{Abbreviations}

AMI: Acute myocardial infarction; CABG: Coronary artery bypass graft; CAM: Confusion assessment method; DSM-IV: Diagnostic and Statistical Manual of Mental Disorders; ICU: Intensive care unit; LRT: Likelihood Ratio Test; MCl: Mild Cognitive Impairment; MMSE: Mini mental state examination; OIT: Orotracheal intubation time; OR: Odds ratio; VFT: Verbal fluency test

\section{Acknowledgements}

None

\section{Funding}

The present study was partially granted by Conselho Nacional de Desenvolvimento Científico e Tecnológico - CNPq, Coordenação de aperfeiçoamento de pessoal de nível superior - CAPES, and Fundação Universidade Estadual do Ceará FUNECE.

\section{Availability of data and materials}

The datasets generated and analyzed during the current study are available from the corresponding author on reasonable request.

\section{Authors' contributions}

Regarding author's contributions, $\mathrm{FRO}$ and $\mathrm{BC}$ had the original idea and designed the study, FRO, VHO and IMO collected all data, FRO, VHO, BC, DMG, DC, IMO, and JWL analyzed the data, JWL elaborated the statistical analysis and wrote the statistical session of the manuscript. FRO and BC wrote the manuscript and all authors approved it.

\section{Ethics approval and consent to participate}

Local ethical committee (Comissão de Ética para Análise de Projetos de Pesquisa - CAPPesq from Hospital das Clínicas da Faculdade de Medicina da Universidade de São Paulo) has approved the protocol under the number $825 / 11$. Written informed consent was obtained from all patients according to international guidelines.

\section{Consent for publication}

Not applicable.

\section{Competing interests}

The authors of the present study declare that they have no competing interests.

\section{Publisher's Note}

Springer Nature remains neutral with regard to jurisdictional claims in published maps and institutional affiliations.

\section{Author details}

${ }^{1}$ Heart Institute (InCor), University of Sao Paulo, Brazil. Av. Dr. Enéas Carvalho de Aguiar 44, Sao Paulo, CEP, São Paulo 05403-000, Brazil. ²Universidade Estadual do Ceará, Fortaleza, Brazil. ${ }^{3}$ Hospital de Messejana Dr. Carlos Alberto Studart Gomes SESA, Fortaleza, Ceará, Brazil.

\section{Received: 31 August 2017 Accepted: 23 January 2018}

\section{Published online: 01 February 2018}

\section{References}

1. Rudolph JL, Inouye SK, Jones RN, Yang FM, Fong TG, Levkoff SE, et al. Delirium: an independent predictor of functional decline after cardiac surgery. J Am Geriatr Soc. 2010;58:643-9.

2. Sockalingam S, Parekh N, Bogoch II, Sun J, Mahtani R, Beach C, et al. Delirium in the postoperative cardiac patient: a review. J Card Surg. 2005;20(6):560-7.

3. Kazmierski J, Kowman M, Banach M, Fendler W, Okonski P, Banys A, et al Incidence and predictors of delirium after cardiac surgery: results from the IPDACS study. J Psychosom Res. 2010;69(2):179-85.

4. Lin Y, Chen J, Wang Z. Meta-analysis of factors which influence delirium following cardiac surgery. J Card Surg. 2012;27:481-92.

5. Guenther U, Theuerkauf N, Frommann I, Brimmers K, Malik R, Stori S, et al. Predisposing and precipitating factors of delirium after cardiac surgery. A prospective observational cohort study. Ann Surg. 2013;257:1160-7.

6. Rudolph JL, Marcantonio ER. Postoperative delirium: acute change with long-term implications. Anesth Analg. 2011;112:1202-11.
7. PHF B, SMD B, Campacci SR, Juliano Y. O mini-exame do estado mental em uma população geral: impacto da escolaridade. Arq Neuropsiquiatr. 1994;52:1-7.

8. Brucki SMD, Malheiros SMF, Okamoto IH, Bertolucci PHF. Dados normativos para o teste de fluência verbal categoria animais em nosso meio. Arq Neuropsiquiatr. 1997;55:56-61.

9. Inouye SK, van Dyck CH, Alessi CA, Balkin S, Siegal AP, Horwitz Rl. Clarifying confusion: the confusion assessment method. A method for detection of delirium. Ann Intern Med. 1990;113:941-8.

10. Ely EW, Inouye SK, Bernard GR, Gordon S, Francis J, May L, et al. Delirium in mechanically ventilated patients. Validity and reliability of the confusion assessment method for the intensive care unit (CAM-ICU). JAMA. 2001;286:2703-10.

11. Blazer DG, van Nieuwenhuizen AO. Evidence for the diagnostic criteria of delirium: an update. Curr Opin Psychiatry. 2012;25:239-43.

12. Bellomo R, Kellum JA, Ronco C. Defining and classifying acute renal failure: from advocacy to consensus and validation of the RIFLE criteria. Intensive Care Med. 2007:33:409-13.

13. http://www.saude.pr.gov.br/arquivos/File/OSEGURANCA_DO_PACIENTE/ modulo2.pdf. Accessed 29 Jan 2018.

14. van Belle G. Statistical rules of thumb. 2nd ed. New Jersey: John Wiley and Sons; 2008.

15. Hosmer DW, Lemeshow S Jr, Sturdivant RX. Applied logistic regression. 3rd ed. New Jersey: John Wiley and Sons; 2013.

16. Arenson BG, MacDonald LA, Grocolt HP, Hiebert BM, Arora RC. Effect of intensive care unit environment on in-hospital delirium after cardiac surgery. J Thorac Cardiovasc Surg. 2013;146(1):172-8.

17. Jones RN, Yang FM, Zhang Y, Kiely DK, Marcantonio ER, Inouye SK. Does educational attainment contribute to risk for delirium? A potential role for cognitive reserve. J Gerontol A Biol Sci Med Sci. 2006;61:1307-11.

18. Stern Y, Gurland B, Tatemichi TK, Tang MX, Wilder D, MayeuX R. Influence of education and occupation on the incidence of Alzheimer's disease. JAMA. 1994;271:1004-10.

19. Sprung J, Roberts RO, Weingarten TN, Cavalcante AN, Knopman DS, Petersen $\mathrm{RC}$, et al. Postoperative delirium in elderly patients is associated with subsequente cognitive impairment. Br J Anaesth. 2017;119(2):316-23.

20. Sauër AC, Veldhuijzen DS, Ottens TH, Slooter AJC, Kalkman CJ, van Dijk D. Association between delirium and cognitive change after cardiac surgery. Br J Anaesth. 2017:119(2):308-15.

21. Norkienè I, Ringaitienè D, Kuzminskaitè V, Šipylaitė J. Incidence and risk factors of early delirium after cardiac surgery. Bio Med Res Int 2013;2013:323491.

22. Koster S, Hensens AG, van der Palen J. The long-term cognitive and functional outcomes of postoperative delirium after cardiac surgery. Ann Thorac Surg. 2009:87:1469-74.

23. Saczynski JS, Marcantonio ER, Quach L, Fong TG, Gross A, Inouye SK, et al. Cognitive trajectories after postoperative delirium. N Engl J Med. 2012;367: 30-9.

24. Rudolph JL, Schreiber KA, Culley DJ, McGlinchey RE, Crosby G, Levitsky S, et al. Measurement of postoperative cognitive dysfunction after cardiac surgery: a systematic review. Acta Anaesthesiol Scand. 2010;54:663-77.

25. Jodati A, Safaie N, Raoofi M, Ghorbani L, Ranjbar F, Noorazar G, et al. Prevalence and risk factors of postoperative delirium in patients undergoing open heart surgery in northwest of Iran. J Cardiovasc Thorac Res. 2013;5(3):97-9

26. Joudi M, Fathi M, Harati H, Joudi M, Izanloo A, Rahdari A, et al. Evaluating the incidence of cognitive disorder following off-pump coronary artery bypasses surgery and its predisposing factors. Anesth Pain Med. 2014;4:e18545.

27. Zaal IJ, Devlin JW, Peelen LM, Slooter AJC. A systematic review of risk factors for delirium in the ICU. Crit Care Med. 2015:43:40-7.

28. Huai J, Ye X. A meta-analysis of critically ill patients reveals several potential risk factors for delirium. Gen Hosp Psychiatry. 2014;36:488-96.

29. Barr J, Fraser GL, Puntillo K, Ely EW, Gélinas C, Dasta JF, et al. Clinical practice guidelines for the management of pain, agitation and delirium in adult patients in the intensive care unit. Crit Care Med. 2013;41:263-306.

30. Rudolph JL, Babikian VL, Treanor P, Pochay VE, Wigginton JB, et al. Microemboli are not associated with deliriumafter coronary artery by-pass graft surgery. Perfusion. 2009;24(6):409-15.

31. Schneider F, Onnasch JF, Falk V, Walther T, Autschbach R, Mohr FW. Cerebral microemboli during minimally invasive and conventional mitral valve operations. Ann Thorac Surg. 2000;70(3):1094-7. 
32. Santos FS, Velasco IT, Fráguas $R \mathrm{~J}$. Riskfactors for delirium in the elderly after coronary artery bypass graft surgery. Int Psychogeriatr. 2004;16(2):175-93.

33. Andrejaitiene J, Sirvinskas E. Early post-cardiac surgery delirium risk factors. Perfusion. 2011;27(2):105-12.

34. Gosselt ANC, Slooter AJC, Boere PRQ, Zaal IJ. Risk factors for delirium after on-pump cardiac surgery: a systematic review. Crit Care. 2015;19:346.

35. Shadvar K, Baastani F, Mahmoodpoor A, Bilehjani E. Evaluation of the prevalence and risk factors of delirium in cardiac surgery ICU. J Cardiovasc Thorac Res. 2013;5(4):157-61.

36. Bucerius J, Gummert JF, Borger MA, Walther T, Doll N, Falk V, et al, Predictors of delirium after cardiac surgery delirium: effect of beating-heart (off-pump) surgery. J Thorac Cardiovasc Surg. 2004;127(1):57-64.

37. Gottesman RF, Grega MA, Bailey MM, et al. Delirium after coronary artery bypass graft surgery and late mortality. Ann Neurol. 2010;67(3):338-44.

38. Lima DP, Ochiai ME, Lima AB, Curiati JAE, Farfel JM, Filho WJ. Delirium in hospitalized elderly patients and post-discharge mortality. Clinics. 2010;65:251-5.

39. McCusker J, Cole M, Abrahamowicz M, Primeau F, Belzile E. Delirium predicts 12-month mortality. Arch Intern Med. 2002;162:457-63.

40. Rockwood K, Cosway S, Carver D, Jarrett P, Stadnyk K, Fisk J. The risk of dementia and death after delirium. Age Ageing. 1999;28(6):551.

41. Burkhart CS, Siegemund M, Steiner LA. Cerebral perfusion in sepsis. Crit Care. 2010;14:215

42. Vincent JL. Ventilator-associated pneumonia. J Hosp Infect. 2004;57:272-80 Review

\section{Submit your next manuscript to BioMed Central and we will help you at every step:}

- We accept pre-submission inquiries

- Our selector tool helps you to find the most relevant journal

- We provide round the clock customer support

- Convenient online submission

- Thorough peer review

- Inclusion in PubMed and all major indexing services

- Maximum visibility for your research

Submit your manuscript at www.biomedcentral.com/submit 